\title{
Listening Strategy Use for Different Text Types
}

\author{
I-Ju Chen ${ }^{1, *}$ \\ ${ }^{1}$ Department of Applied Foreign Languages, Ling Tung University, Taichung, Taiwan \\ *Correspondence: Department of Applied Foreign Languages, Ling Tung University, No. 1, Ling Tung Rd., Nantun \\ Dist., 408 Taichung, Taiwan. E-mail: p10127@teamail.ltu.edu.tw
}

Received: June 5, 2017

doi:10.5430/wjel.v7n2p31
Accepted: June 16, 2017 Online Published: June 28, 2017

URL: https://doi.org/10.5430/wjel.v7n2p31

\begin{abstract}
This study sought to discover the listening strategies used by an advanced learner when comprehending different listening texts. A grounded theory design was employed, and using the immediate retrospection research method, specific listening strategies used by the advanced learner were categorized as those assisting comprehension, monitoring comprehension, and enhancing comprehension. Among the identified strategies, some were used for different text types. The patterns of strategies used by the advanced learner were also identified and are discussed.
\end{abstract}

Keywords: listening strategies; advanced learner; grounded theory; immediate retrospection; text types

\section{Introduction}

Listening comprehension has been reported as the cornerstone of language acquisition (Bei \& Xinguang, 2017; Elkhafaifi, 2005; Renukadevi, 2014). The importance of listening comprehension has been attributed to the development of communicative approaches to language teaching over the past three decades (Elkhafaifi, 2005; Renukadevi, 2014) and has resulted in an increase in listening activities in student textbooks and methodology texts designed for listening (Rubin, 1994).

Although listening comprehension is considered critical in language learning, most English as a Foreign Language (EFL) students still have difficulties in comprehending listening texts. These difficulties include unfamiliar vocabulary, speech delivery speed, linking sounds, distraction, memory loads, and interpretation (Renukadevi, 2014; $\mathrm{Su}, 2007$; Vandergrift, 1999;). Because these difficulties are evident during listening comprehension, researchers have requested further investigation into the link between L2 listening level and listening strategies as well as examination of the concept of skilled learners and their online procedures for monitoring and remedying gaps in comprehension (Lynch, 1998; McDough, 1999, as cited in Vandergrift, 2003; Wu, 2007). In light of the hope that "strategies can help students to capitalize on the language input they receive and to improve their performance on listening tasks" (Vandergrift, 1999, p. 171), understanding advanced learners' use of strategies may be helpful for other language learners. Researchers have stated that strategies used by successful listeners may help students master the forms and functions required for comprehension and production when they learn a second language, which thus affect their achievement (Chou, 2016; O’Malley \& Chamot, 1990; Rubin, 1981).

Listening strategies have been defined by previous researchers (Berne, 2004; Field, 1998; Ghoneim, 2013; Nix, 2016; White, 1998). Field (1998) noted that learners usually adopt listening strategies unconsciously in the first language learning situation they encounter. White reported that listening strategies, which are "efforts to compensate for uncertainties in understanding" (1988, p. 9), include inferring, realizing where misunderstandings have occurred, and asking for clarification. More recently, Berne (2004) indicated that learners may take an active role in orienting themselves to the listening task, accessing their background knowledge, and comparing their interpretation of the input with the actual output. On the basis of the definitions proposed in previous studies, listening strategies refer to an action that learners perform to help them comprehend listening texts.

Because listening comprehension strategies can be identified during the process of listening comprehension, many studies have investigated the listening strategies used by highly proficient learners. In an EFL setting, in O'Malley and Chamot's (1990) study, effective listeners were observed to listen to longer chunks of dialogue, infer the meaning of unfamiliar words from the context, and use both top-down and bottom-up approaches, elaborations, and 
self-questioning. Furthermore, Anderson (1996) indicated that more successful listeners appeared to use worldly knowledge, comprehension monitoring, prediction, and summarization more effectively during listening tasks. Certain studies have revealed that more competent EFL learners adopted strategies different from their less competent counterparts. Chao (1996) reported that effective listeners employed functional, self-management, macroconceptual, microperceptual, and social strategies. Teng (1997) determined that effective EFL listeners used more metacognitive and cognitive strategies than ineffective listeners. Wang (2001) claimed that highly proficient listeners exhibited significantly higher frequency use of planning, monitoring, self-evaluation, practicing, bottom-up strategies, top-down strategies, note taking, grouping, and summarization. $\mathrm{Wu}$ (2007) determined that highly proficient listeners used more metacognitive strategies, including self-management, performance evaluation, repetition, and imagery. Kazemi and Kiamarsi (2017) also claimed that advanced learners employed metacognitive strategies more frequently than cognitive and socio-affective strategies, whereas their intermediate counterparts preferred cognitive and socio-affective strategies.

Aside from the vital role of listening strategies in the listening process, in Rubin's (1994) review of previous studies, text type was noted as another critical factor affecting listening comprehension Brown et al. (1985) provided empirical evidence that narrative texts were easier to listen to and recall than expository texts among L2 English-speaking students. Shohamy and Inbar (1991) indicated that the dense and concise nature of news broadcast text may impede comprehension, and redundancies, repetitions, whereas pauses in lecture and dialogue texts may enable learners to activate relevant strategies and may facilitate comprehension. Nevertheless, Berne (1992) noted that text type alone was not a significant factor in L2 listening comprehension, but rather in the comprehension of details. Moreover, Bacon (1992) reported that passage difficulty may influence listeners' strategy choices in different phases of the information-gathering process. More successful listeners were flexible, shifting their strategy in the perceptual and parsing stages. Additionally, Berne's (2004) review of Young's (1997) study revealed that text type and proficiency level may affect the sequence of strategy use. Furthermore, as discussed in Su's (2007) review of the previous studies on text factors and learning strategy choices, several studies have shown that successful learners had the ability to adjust strategies in accordance with the evaluation of various text factor variables, such as text length and difficulty level, rather than adopted specific strategies (Oxford et al., 2004; Yamaroi et al., 2003).

Although previous studies have been conducted to determine the differences in strategy use between effective and less effective listeners, Bacon stated that "only a few studies have investigated L2 listening strategies using a retrospective approach" (1992, p. 162). Therefore, researchers have called for in-depth studies on the listening comprehension process of learners (Brownell, 1996; Underwood, 1994; Wu, 2007). Goh further claimed that "there is still a great deal to be discovered about these differences, not just quantitatively but qualitatively" (1998, p. 125). Even though studies on EFL listening comprehension in Taiwan have been conducted (Ku, 1998; Lee, 1997; Lin, 2000; Teng, 1997), they have mainly adopted quantitative methods to investigate EFL students' opinions and strategy use.

Prior research related to the issue of text type in L2 listening comprehension is sparse. Although previous researchers have claimed that text type has been employed as a variable in L2 listening comprehension (Bacon, 1992; Shohamy \& Inbar, 1991), "such comparisons have rarely been undertaken in L2 language listening comprehension research" (Berne, 1992, p. 6). Previous studies have shown that text type may affect listening comprehension; however, few studies have been conducted on the effect of different types of texts on listening strategy choices. Because success in listening comprehension may be attributed to listening strategy use and text type and listening strategies may enhance learners' listening comprehension, how strategy choice for different text types contributes to learners' success in listening comprehension is worthy of investigation.

The purpose of this study was to investigate the listening strategies used by an advanced listener when comprehending different listening texts using a grounded theory design. In this study, a grounded theory was generated from data obtained and analyzed by comparing the findings of previous studies. The findings of this study will hopefully not only elicit the specific strategies employed in response to specific listening texts, rather than provide a general assessment of learners' typical strategy use across numerous tasks, but also identify variations and patterns in strategy use based on different contexts. In particular, this study sought to answer the following research questions:

1. What are the similarities and differences in the use of listening strategies by the advanced learner in comprehending different texts?

2. What are the patterns of the learner's listening strategy use in different text contexts? 


\section{Method}

\subsection{Participant}

The participant was an EFL student who passed the listening section of the Advanced Level of the General English Proficiency Test (GEPT). The GEPT, developed by the Language Training and Testing Center in Taiwan, is a standardized English proficiency test that is divided into five levels: Elementary, Intermediate, High-Intermediate, Advanced, and Superior. Each level involves listening, reading, writing, and speaking sections. At the age of 30, the participant had more than 15 years of English learning experience and had obtained a master's degree in English Literature. The participant was a high-school English teacher at the time of her participation.

\subsection{Instruments}

Four listening tasks with comprehension questions were employed as texts with which to elicit possible strategy use for listening comprehension. Two dialogues and two monologues were taken from the High-Intermediate Level of the GEPT ( $2002 \& 2003)$. The two dialogue passages were consultative dialogues that involved constant interaction between two interlocutors. The dialogues were characterized by simple sentences, colloquial language, and many repetitions and pauses. One dialogue was a phone conversation dealing with a registration, whereas the other was a discussion about transportation. Both passages involved constant interaction and a high degree of shared knowledge. The monologue passages were a news report and a lecture. The news report, regarding a survey of the internet, was a prewritten and edited monologue. The lecture, concerning a species of wolves, was a monologue based on written notes. With no interaction between speaker and addressees, the information was presented as novel information rather than shared knowledge. The monologue passages were characterized by more complex sentences, formal language, and a lack of repetition or pauses. The follow-up questions for each passage were used to check the participant's listening comprehension and to explore possible testing strategies that can be employed when doing these tests. The two dialogue passages had one associated comprehension question each, whereas the two monologue passages had two associated comprehension questions each.

The immediate retrospective technique and the face-to-face interview were used to facilitate the process of strategy report for the listening tasks. According to Nunan (1992), procedures of retrospection used to gauge test-taking performance include the task delivery followed by think-aloud procedures and face-to-face interviews. In this study, after listening to the passages and completing the comprehension questions, the participant was asked to retrospect to the texts sentence by sentence. The researcher asked the participant a series of interview questions to elicit the strategies that she used for comprehending the listening texts.

\subsection{Procedures}

First, the participant was allowed to listen to the dialogue about the transportation comparison and was asked to complete the comprehension question. Subsequently, the participant was asked to retrospect to the text sentence by sentence. Pauses were allowed at the participant's request, which gave the participant enough time to verbalize her thoughts. Next, the participant was asked to comment on her behavior and answer the interview questions regarding the steps she employed before listening to the dialogue and the strategies she used to answer the comprehension questions.

The second dialogue about a registration at a clinic was conducted using the same procedure. Each task lasted approximately 50 minutes with a rest interval of 2 hours. The procedure was used again for the monologue about the internet report 1 week later, and for the monologue about the species of wolves, which was employed 1 day after the first monologue. Both of the monologue texts lasted approximately 90 minutes.

\subsection{Data Analysis}

The retrospective protocols were recorded and transcribed verbatim. With the use of the constant comparison method, the strategies reported by the participant were identified, categorized, and synthesized into different types. Strategy uses for different listening text types were further compared to determine their similarities and differences. Finally, patterns of strategy use were concluded based on different text and context types.

\section{Results and Discussion}

\subsection{Categories of Strategies Used Across Text Types}

The results showed that the advanced learner used a variety of strategies when comprehending different texts. On the basis of the data, the following 18 strategies were identified: (1) prediction, (2) using background knowledge, (3) 
listening for key words, (4) grammar analysis, (5) note taking, (6) inferring the context, (7) message integration, (8) translation, (9) visualization, (10) reinterpretation, (11) selection of strategies, (12) increasing concentration, (13) prediction confirmation, (14) problem identification, (15) selective attention, 16) evaluation, (17) recalling the main idea, and (18) deleting impossible answers. The 18 strategies were further categorized into three groups based on their function: assisting comprehension, monitoring comprehension, and enhancing comprehension. Among these, assisting comprehension comprised the strategies of prediction, using background knowledge, listening for key words, grammar analysis, note taking, inferring the context, message integration, translation, visualization, reinterpretation, and recalling the main idea. The strategies in this group were among the cognitive strategies proposed by Bacon (1992). However, translation was previously identified in lower-level students' strategy use (Vandergrift, 2003), which contradicts the finding of the present study that the advanced learner used many translation strategies when comprehending the monologues. The advanced learner used the strategy of translation only for the monologues, in which complex, difficult, and long sentences appeared. Monitoring comprehension covered six substrategies: selection of strategies, increasing concentration, prediction confirmation, problem identification, selective attention, and evaluation. The strategies in this group were among the metacognitive strategies defined by Vandergrift (1999). Finally, the strategy of deleting impossible items belonged to the strategy group named enhancing comprehension. This implies that the advanced learner not only adopted both cognitive and metacognitive strategies but also acquired the ability to suppress irrelevant information. Vandergrift stated that "if the conceptual frame is not well enough developed to suppress irrelevant information, elaborations and inferences will remain superficial and never coherent mental representation of the text" $(2003, p$. 486). In this circumstance, the strategy of deleting impossible items was vital for filtering irrelevant information to generate metacognitive strategies at a deep level.

By contrast, the synthesis of the aforementioned strategies revealed that six strategies were observed to be employed for both the different text types. Four strategies assisting comprehension (prediction, listening for key words, grammar analysis, and recalling the main idea), one strategy monitoring comprehension (selection of strategies), and one strategy enhancing comprehension (deleting impossible items) were similar strategies used across text types. According to Bacon (1992), the strategies of listening for keywords, grammar analysis, and recalling the main idea are bottom-up strategies, whereas prediction strategy is a top-down strategy. The participant not only adopted metacognitive strategies but also used cognitive strategies for both bottom-up and top-down processing. The finding that the advanced learner used many listening strategies to achieve understanding of different texts confirms the statement of Vandergrift (2003) that highly skilled listeners are characterized by flexible use of both top-down and bottom-up processes when interacting with the input. Goh (1998) also proposed the same profile of high-ability listeners; that they engage extensively in top-down and bottom-up processes.

\subsection{The Strategy Use Patterns of the Learner}

Four patterns were discovered in the learner's strategy use: transferability, variation, combination, and prioritizing.

Transferability. Some strategies were used across text types: prediction, listening for key words, selection of strategies, and deleting impossible items. The following are some excerpts of the usage patterns.

Excerpt 1:

"I will predict the content of the passage using the four items" (dialogue and monologue).

Excerpt 1 shows that the learner predicted the content by analyzing the items of the multiple-choice comprehension question in the pre-listening phase.

Excerpt 2:

"I heard the words 'drawback,' 'transportation,' 'convenient,' and noticed those important words because

they are long words" (dialogue).

“'Picture' is the key word; 'destructive' and 'wolves' are the key words" (monologue).

Except 2 demonstrates that the learner paid attention to key words while listening across all text types.

Excerpt 3:

"I know there will be numbers, so I need paper and a pen to take notes" (dialogue).

"For these long and complex monologues, I need to take notes of all the key words" (monologue).

Except 3 shows that when numbers or unfamiliar text was anticipated, the learner decided which strategy to use to overcome difficulties, such as taking notes or paying extra attention. 


\section{Excerpt 4: \\ "The word 'registration' may be used in (A) a hospital and (C) a university, but it is not used in (B) a restaurant or (D) a barbershop. (B) and (D) need the word 'reservation' not 'registration.' Actually, 'registration' in a university means 'enroll,' not make an 'appointment'” (dialogue). \\ "(B) Although the speaker mentioned red wolves, she did not provide further information;" "(C) No single wolves were mentioned;" “(D) I did not hear anything about adult wolves;” “(C) I didn't hear the word "dangerous"' (monologue).}

As outlined in Except 4, the learner deleted impossible items by recognizing unmentioned words and distracting items. This pattern confirms the statement in Macaro's (2006) review of Anderson's study that "strategies are transferred to similar tasks by a procedure involving pattern matching through which the learner perceives similarities between the new task and former tasks where strategies were applied" (2000, p. 329). Macaro (2006) further asserted that learner strategies are transferable to other situations or tasks.

Variation. Another of the identified patterns was that the learner used a greater variety of strategies for certain text types than others. Strategy variation for the monologues appeared to be greater than for the dialogues. Excerpt 5 shows that the learner identified listening difficulties and was aware of listening problems, such as longer and complex sentences.

\section{Excerpt 5:}

"I need to take notes for long and difficult sentences, or I will miss the main points."

The results showed that as the complexity of a passage increased, variety of strategy use appeared. Active learners outperform passive learners in the range and type of listening strategies they employ (Taherkhani, 2011). This finding also echoes the result of Defilippis's (1980) study that certain types of listening strategies appear to be partially dependent on task demands. The advanced learner in the present study used a greater variety of strategies when the complexity and difficulties of the text increased. Rubin also indicated that more proficient listeners tend to use a strategy called "wide distribution" (1994, p. 211); that is, open and flexible use of strategies. Berne's (2004) review of the studies of Murphy $(1986,1987)$ revealed that more proficient listeners used numerous strategies.

Moreover, approaches to using the strategies varied. When using prediction, the learner only used the items in the comprehension question to predict the content of the dialogue; for monologues, however, the learner predicted the content from the items and from the description of the text. When using the strategy of listening for key words, the learner identified key words as longer words spoken clearly and statements with certain sentence patterns, persons, time, or examples in dialogue type. Nevertheless, the learner identified key words as nouns related to the topic of the text for the monologues. The results indicate that the advanced learner varies strategy use when encountering passages of different complexity. The same strategies used in different patterns are accordant with Goh's assertion that "individual learners used a number of tactics for each strategy identified and they were able to vary tactics within the same strategic approach, depending on the situation" (1998, p. 141). Similarly, Vogely's (1995) review of Laviosa's (1991) study showed that advanced students differed more in the manner in which they applied strategies rather than in the types of strategies they used.

Combination. This pattern showed that a series of strategies were combined by the learner to overcome difficulties. For example, when the message was related to numbers, the learner repeated the numbers, halved these numbers, and closed her eyes to increase her concentration. When the participant listened to the monologue passages, which were characterized by more complex sentences, she used note taking, translation, reinterpretation, problem identification, and selective attention. When encountering different comprehension texts, various strategies were combined. Berne's (2004) review of Goh's study noted that "although individual tactics were useful, successful comprehension also depended on whether the learner was able to combine various mental tactics in a way that could truly enhance comprehension" (2002, p. 203). When encountering different listening comprehension texts, advanced learners "deploy strategies in clusters appropriate to contexts and text" (Macaro, 2006, p. 327).

Prioritizing. Another finding is that certain strategies were used before others. In the prelistening phase, the learner reviewed the comprehension item first to predict the content of passages before listening. In the listening phase, when the learner encountered listening difficulties, a sequence of strategy use appeared. For example, the learner used the following strategies in sequence. First, she predicted number messages, stating "I think a series of number will be stated later." Second, she identified the problem by saying that "numbers are my weakness." Third, she selected the note taking strategy, stating "I need to take notes." Fourth, she visualized the number by saying "479 
thousand-000 will appear in my brain." Finally, she took notes, saying "Take notes of the numbers." Another example was that when the learner encountered unfamiliar information, she first identified the problem by stating "Here I don't have the background knowledge and I am not familiar with wolves;" then she paid attention to the message to overcome the problem, stating "The only thing I need to do is wait for and pay attention to the information." In the post-listening phase, the learner recalled the main idea and deleted the impossible items to perform more favorably in the listening comprehension test. The results show that the advanced learner tended to prioritize a series of strategies in different listening phases when encountering listening difficulties and unfamiliar texts. The sequential use of strategies echoes Berne's (2004) review of Young's (1997) study that learners tended to use strategies sequentially. The sequence included employing inferencing to guess the topic of the text, followed by summarizing to reinforce interpretation of the text. Afterward, learners interacted with the text by making comments. Under these circumstances, the priority of strategy use was found as a pattern across text types.

\section{Conclusion}

The present study successfully investigated strategies used for the comprehension of different listening texts and elicited patterns of strategy use across text types. Although the findings provide information about the similarities, differences, and patterns of strategy use, this study had some limitations that should be taken into consideration. As a case study, this study involved only one participant who had a background in education. The result may thus be applicable to learners with a similar background. Participants with other educational backgrounds should be included to improve the findings of the study. The other limitation lies in the different types of listening texts used. In this study, only four texts were involved. Because text type affects the use of strategies, as shown in this study, further research is suggested to include more text types to obtain more comprehensive findings regarding this topic.

\section{References}

Anderson, N. J. (1996). Increasing metacognitive awareness in the L2 classroom by using think-aloud protocols and other verbal report formats. In R. Oxford (Eds.), Language Learning Strategies Around the World: Cross-cultural Perspectives. (pp.1-18). University of Hawaii, Manoa: Second Language Teaching \& Curriculum Center.

Bacon, S. M. (1992). The relationship between gender, comprehension, processing strategies, and cognitive and affective response in foreign language listening. The Modern Language Journal, 76(2), 160-178. https://doi.org/10.1111/j.1540-4781.1992.tb01096.x

Bei, Z., \& Xinguang, S. (2017). A study of Chinese college students' English listening strategies. Advances in Social Sciences Research Journal, 4 (1), http://dx.doi.org/10.14738/assrj.42.2619

Berne, J. E. (1992). The role of text type, assessment task, and target language experience in L2 listening comprehension assessment. Paper presented at the Annual Meetings of the American Association for Applied Linguistics and the American Association of Teachers of Spanish and Portuguese, 1-45.

Berne, J. E. (2004). Listening comprehension strategies: A review of the literature. Foreign Language Annals, 37(4), 521-531. https://doi.org/10.1111/j.1944-9720.2004.tb02419.x

Brownell, J. (1996). Listening: Attitudes, principles, and skills. Boston, MA: Allen \& Bacon.

Chao, Y. G. (1996). The influence of strategy use on comprehension and recall of authentic English listening texts by Chinese EFL students in Taiwan. Unpublished doctoral dissertation, University of Minnesota, Minnesota.

Chou, M. H. (2016). Strategy use for listening in English as a foreign language: A comparison of academic and vocational high school students. TESOL Journal, 7(3), 513-539. https://doi.org/10.1002/tesj.214

DeFilippis, D. A. (1980). A study of the listening strategies used by skillful and unskillful college French students in aural comprehension tasks. (Doctoral dissertation, University of Pittsburgh, 1980). Dissertation Abstracts International, 41, 2481A.

Elkhafaifi, H. (2005). The effect of pre-listening activities on listening comprehension in Arabic learners. Foreign Language Annals 38(4), 505-513. https://doi.org/10.1111/j.1944-9720.2005.tb02517.x

Field, J. (1998). Skills and strategies: Towards a new methodology for listening. ELT Journal, 52, 110-118. https://doi.org/10.1093/elt/52.2.110 
Ghoneim, N. M. M. (2013). The listening comprehension strategies used by college students to cope with the aural problems in EFL classes: An analytical study. English Language Teaching, 6(2), 100-112.

Goh, C. C. M. (1998). How ESL learners with different listening abilities use comprehension strategies and tactics. Language Teaching Research, 2(2), 124-147. https://doi.org/10.1191/136216898667461574

Kazemi, A., \& Kiamarsi, S. (2017). An Investigation into Listening Comprehension Strategies and the Relationship between Listening Comprehension Strategies and Overall Proficiency Level of Intermediate and Advanced Learners. Journal of Language Teaching and Research, 8(1), 149-156. http://dx.doi.org/10.17507/j1tr.0801.18

Ku, P. Y. (1998). Strategies associated with listening comprehension of EFL students in Taiwan. The Proceedings of the Seventh International Symposium on English Teaching (p.581-591). Taipei: Crane.

Lee, H. (1997). A study of the listening comprehension strategies of junior college EFL students in Taiwan. The Proceedings of the Fourteenth Conference on English Teaching and Learning in R.O.C. (p. 393-412). Taipei: Crane.

Lin, S. H. (2000). A study of English listening comprehension strategies used by senior high school students in Taiwan. Unpublished Master Thesis, National Kaohsiung Normal University, Kaohsiung, Taiwan.

Macaro, E. (2006). Strategies for language learning and for language use: Revising the theoretical framework. The Modern Language Journal, 90(3), 320-337. https://doi.org/10.1111/j.1540-4781.2006.00425.x

Nix, J. M. L. (2016). Measuring latent listening strategies: Development and validation of the EFL listening strategy inventory. System, 57, 79-97. https://doi.org/10.1016/j.system.2016.02.001

O’Malley J. M., \& Chamot, A. U. (1990). Learning strategies in second language acquisition. New York: Cambridge University Press. https://doi.org/10.1017/CBO9781139524490

Renukadevi D. (2014). The role of listening in language acquisition; the challenges \& strategies in teaching listening. International Journal of Education and Information Studies, 4(1), 59-63.

Rubin, J. (1981). The study of cognitive process in second language learning. Applied Linguistics, 11(2), 117-131. https://doi.org/10.1093/applin/II.2.117

Rubin, J. (1994). A review of second language listening comprehension research. The Modern Language Journal, 78(2), 199-221. https://doi.org/10.1111/j.1540-4781.1994.tb02034.x

$\mathrm{Su}, \mathrm{S}$. W. (2007). A study of the effects of text type on college student's listening strategy choice while taking listening comprehension test. Unpublished Master's thesis of National Changhua University of Education, Changhua, ROC.

Taherkhani, R. (2011). Active and Passive Students' Listening Strategies. Journal of Language Teaching and Research, 2(3), 705-708. https://doi.org/10.4304/j1tr.2.3.705-708

Teng, H. C. (1997). An investigation of listening comprehension strategies. English Teaching and Learning 21(3), 24-39.

The Language Training \& Testing Center. (2002). General English Proficiency Test: High-Intermediate Level. Taipei: The Language Training \& Testing Center.

The Language Training \& Testing Center. (2003). General English Proficiency Test: High-Intermediate Level. Taipei: The Language Training \& Testing Center.

Underwood, M. (1994). Teaching listening ( ${ }^{\text {th }}$ ed.). New York: Longman

Vandergrift, L. (1999). Facilitating second language listening comprehension: Acquiring successful strategies. ELT Journal, 53(3), 168-176. https://doi.org/10.1093/elt/53.3.168

Vandergrift, L. (2003). Orchestrating strategy use: Toward a model of the skilled second language listener. Language Learning, 53(3), 463-496. https://doi.org/10.1111/1467-9922.00232

Vogely, A. (1995). Perceived strategy use during performance on three authentic listening comprehension tasks. Modern Language Journal, 79(1), 41-56. https://doi.org/10.1111/j.1540-4781.1995.tb05414.x

Wang, W. I. (2001). Effects of gender and proficiency on listening comprehension strategy use by Taiwanese EFL senior high school students-A case from Changhua, Taiwan. Unpublished Master's thesis of National Changhua University of Education, Changhua, ROC.

White, G. (1998). Listening. Cambridge: Cambridge University Press. 
Wu, C. H. (2007). A study of listening strategies and difficulties of high-proficiency and low-proficiency English majors in Taiwan-A think-aloud study. Unpublished Master's thesis of National Changhua University of Education, Changhua, ROC. 